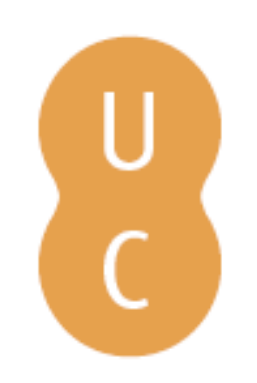

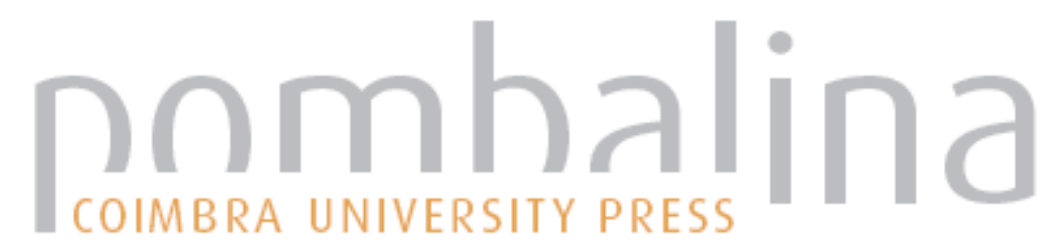

\title{
Sófocles y Antonin Artaud: la tragedia y el teatro de la crueldad: tensión y desgarro de una interioridad perdida
}

\author{
Autor(es): $\quad$ Mallearel, Jorge \\ Publicado por: Centro de Estudos Clássicos e Humanísticos da Universidade de \\ URL \\ persistente: \\ DOI: \\ Coimbra; Imprensa da Universidade de Coimbra \\ URI:http://hdl.handle.net/10316.2/30251 \\ DOI:http://dx.doi.org/10.14195/978-989-721-038-9_32 \\ Accessed : $\quad$ 26-Apr-2023 10:23:10
}

A navegação consulta e descarregamento dos títulos inseridos nas Bibliotecas Digitais UC Digitalis, UC Pombalina e UC Impactum, pressupõem a aceitação plena e sem reservas dos Termos e Condições de Uso destas Bibliotecas Digitais, disponíveis em https://digitalis.uc.pt/pt-pt/termos.

Conforme exposto nos referidos Termos e Condições de Uso, o descarregamento de títulos de acesso restrito requer uma licença válida de autorização devendo o utilizador aceder ao(s) documento(s) a partir de um endereço de IP da instituição detentora da supramencionada licença.

Ao utilizador é apenas permitido o descarregamento para uso pessoal, pelo que o emprego do(s) título(s) descarregado(s) para outro fim, designadamente comercial, carece de autorização do respetivo autor ou editor da obra.

Na medida em que todas as obras da UC Digitalis se encontram protegidas pelo Código do Direito de Autor e Direitos Conexos e demais legislação aplicável, toda a cópia, parcial ou total, deste documento, nos casos em que é legalmente admitida, deverá conter ou fazer-se acompanhar por este aviso.

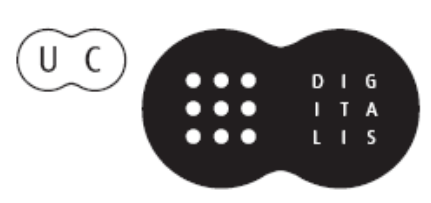




\section{De ayer a hoy}

\section{Influencias clásicas en la literatura}

\section{Aurora López, Andrés Pociña, Maria de Fátima Silva (coords.)}




\title{
Sófocles y Antonin Artaud. \\ LA TRAGEDIA Y EL TEATRO DE LA CRUELDAD: TENSIÓN Y DESGARRO DE UNA INTERIORIDAD PERDIDA
}

Jorge Mallearel

Universidad de Morón

\begin{abstract}
Intentarenmos pensar, desde el carácter trágico del teatro griego del siglo $\mathrm{V}$ a. C., los conflictos insolubles que puede albergar cualquier existencia humana. En efecto, aquellas tragedias al dramatizar los padecimientos sufridos por sus héroes o heroínas de-velaban una precariedad existencial universal. Esta percepción nos impulsó a dos reflexiones. La primera: a pensar el escenario trágico como el sitio donde se plasmaba la interioridad más despojada, siendo este escenario el vehículo descarnado por el que el hombre cobra conciencia de su "incompletitud". La segunda: a mostrar que estas expresiones despojadas desgarran a los discursos de las prácticas jurídicas y morales.
\end{abstract}

\section{Introducción}

Las tragedias suelen mostrar una cara excepcional del hombre. Los contratiempos de sus personajes se empobrecen frente a un análisis moral o jurídico. Es posible que las comunidades se desplomaran con la habitualidad del incesto, o con un ejército de "Medeas" que decidieran resolver sus celos apuñalando el cuerpo inocente de sus hijos. No obstante, es sabido que nadie está libre de experimentar estas denominadas aberraciones. Quizás es la aitia o necesidad la que abraza a cualquier individuo y lo lleva a esas experiencias "hiperbólicas". Aunque las narraciones psicológicas y los escritos del derecho busquen atenuar esos paroxismos - una encasillando, la otra con castigo y encierro - ello no impide su flujo. Lo ingobernable aparece sin más. Esa corriente de hybris, de desmesura, empuja al hombre al abismo de aquello que late en él, aún sin que lo sepa, no porque sea parte de su yo inconciente, sino porque es la tensión propia del ser, o de fuerzas misteriosas que empujan por salir y extinguirse. Existe en todo hombre un potencial oculto, pero disimulado detrás de conductas y símbolos. Dicha potencialidad in-definida anida en la naturaleza bumana, nos ronda. Está más allá de toda determinación o "biografía". Es una naturaleza sin contornos, como los restos de una violenta extinción o conflagración. La tragedia griega suele presentar ante el público, en las desdichas de sus personajes, este estado de apertura. Artaud, con el teatro de la crueldad quiere dar cuenta de ese estado, lamentándose de la dramaturgia psicológica, la cual recorta, según él, "escenas íntimas de la vida de unos pocos fantoches, transformando al público en voyeur $[. .$.$] nos han$ 
desacostumbrado (sigue) a esa acción inmediata y violenta que debe tener el teatro" ${ }^{\prime}$.

\section{E1 héroe sometido.}

Las expresiones vertidas nos conducen a pensar que algo incontrolable brota entre los pliegos de la naturaleza, del mismo modo que cuando en una sociedad se instala una peste, loimós. Ésta, arrasa sin piedad, se lleva en su torbellino todos los límites. Los muertos yacen tirados en la vía pública, las casas no vuelven a cerrarse, los cementerios se colman. En Edipo surge algo similar, pues sus límites comienzan a desvanecerse. Puede suponerse que él configura o reúne en sí, más que el sueño no resuelto de matar al padre y el deseo por su madre, una disolución y una generación. Por un lado, se disuelven las certezas absolutas: la de ser rey, amante y padre. Por otro, en Edipo se genera una vivencia: la infinitud compleja y ambigua del hombre.

Tomaremos a Edipo para revelar que detrás de la religiosidad de los mitos que invocan las obras trágicas aparece oculta una "vacilación", debido a la mezcla de dos planos: el divino y el humano. Así, para que la conciencia trágica se presente, dice Vernant "es preciso, en efecto, que los planos humanos y divinos sean lo bastante distintos para oponerse [...] sin cesar, sin embargo, de aparecer como inseparables". ${ }^{2}$ La huella divina es portadora de una oposición o conflicto que algunas dramatizaciones saben desandar. Conflicto que no es cualquier conflicto, éste es insoluble, y se debe a que en el plano divino todo es posible sin luchas. En el hombre también todo es posible, pero no sin una guerra interior.

Edipo, Medea, Antígona, viven ese agonismo, esa guerra, pero fatalmente. Fatalidad que conduce generalmente a una disolución. En el rey Edipo, dicha disolución se dio rápidamente. Tanto como padre, esposo, hijo y hermano. ¿Cuál es el rostro de Edipo? Exclama él mismo: "soy hijo de impuros, tengo hijos comunes con aquella de la que yo mismo -¡desdichado!- nací”3. Si pensamos que toda biografía es un límite, Edipo es carencia de biografía, pues en su figura los límites se van desplomando. ¿Quién es en verdad? Su contorno no es claro: ¿es hermano o padre de Antígona e Ismene? ¿Es Rey o un simple vagabundo que ni casa tiene? Sin embargo, ésta no es una mirada pesimista, precede a todo pesimismo.

Por otro lado, son los temas teatrales que Artaud aceptaría. Pues, para él compondrían, junto a la locura, el crimen y la guerra, temáticas de una metafísica que no busca una verdad última. Seguramente sospecha que el teatro

\footnotetext{
${ }^{1}$ Artaud, 1964: 87.

${ }^{2}$ Vernant J. P., 2002: 85.

${ }^{3}$ Sófocles, 1977: 1361.
} 
que abandona esta dirección más universal, sólo relata pequeñas vicisitudes domésticas, burguesas. La tragedia edípica hace estallar esta necesidad oculta, y su figura se torna la cara visible que la habitualidad invisibiliza. De este modo, cuando Artaud compara al teatro con la alquimia, que es el doble de una objeto material, dice que "el teatro debe ser considerado también como un Doble, no ya de esa realidad cotidiana y directa de la que poco a poco se ha reducido a ser la copia inerte, tan vana como edulcorada, sino de otra realidad peligrosa y arquetípica, donde los principios, como los delfines, una vez que mostraron la cabeza se apresuran a hundirse otra vez en las aguas oscuras". ${ }^{4}$ En efecto, ciertos temas que estas obras representan asoman como un torbellino siniestro, y tan pronto como se hacen público deben hundirse. Así, velozmente Edipo abandona la ciudad, sale de la vista de todos, se invisibiliza detrás del peregrinar sin rumbo. Presiento que el deseo de estas representaciones es plasmar el horror de la crueldad. En el teatro de Antonin Artaud, esta "crueldad" no se reduce a una definición próxima a lo material. Es decir, no alude a carne quemada, torturada, o a los restos de un cuerpo luego de un festín sangriento. De ningún modo, cuando Artaud habla de la crueldad relata que en ella "hay una especie de determinismo superior [...] una especie de dirección rígida, de sumisión a la necesidad" "Las tragedias parecen volcar ese determinismo y sumisión de carácter devorador. El proyecto artaudeano quiere imponer dicho carácter, en el que el incesto, el parricidio o el filicidio, surgen descarnados, sin maquillajes. Medea, por ejemplo, mata sus hijos porque sus celos son más profundos que el amor hacia sus hijos. Los celos le roen el corazón de tal manera que el "sentimiento materno" retrocede. La cultura, en este acto, se desgarra.

Cierta experiencia trágica griega y la idea que Artaud tiene del teatro intentan evadir el corsé de cualquier conocimiento o vestimenta teórica. Lo expuesto en las tragedias, quizá se asemeja a la experiencia interior que describe Bataille en estos términos: "La experiencia interior responde a la necesidad en la que me encuentro [...] de ponerlo todo en tela de juicio (en cuestión) sin reposo admisible. Esta necesidad funcionaba pese a las creencias religiosas; pero tiene consecuencias tanto más completas cuando no se tienen tales creencias. Las presuposiciones dogmáticas han dado límites indebidos a la experiencia: el que sabe ya, no puede ir más allá de un horizonte conocido" ${ }^{\text {. }}$ Estimo que las tragedias y el teatro de la crueldad parecieran motivados por esa experiencia despojada. Artaud, por su parte, intenta ser fundante, lo cual no implica fundamentar, al estilo de brindar argumentos lógico-racionales que ensayen una explicación. Fundante en cuanto a lo que origina. La palabra griega

\footnotetext{
${ }^{4}$ Artaud, 1964: 49.

${ }^{5}$ Artaud, 1964: 104.

${ }^{6}$ Bataille, 1972: 14.
} 
arkhe es seductora en este sentido, ya que su semántica nos devuelve, además de origen, comienzo y principio, también, mando, poder, autoridad y potencias celestiales. Los significados presentados acuden, de algún modo, a producir la atmósfera teatral. En efecto, por un lado, aparece en escena una naturaleza ingobernable, un poder. Por otro, lo humano se hace súbdito de potencias celestiales, de "autoridades" sobrehumanas que hacen estéril cualquier acción contra esa necesidad implacable.

\section{Ciudad trágica}

Recorrer la tragedia edípica nos permite percibir qué anida en el corazón del héroe y mostrar, a su vez, que este tipo de representaciones son el Doble de esa crueldad que habita en el fondo de lo que denominamos vida. Para tal fin, la tragedia utiliza un material mítico, el cual contiene transgresiones como el incesto, el parricidio o el matricidio. Este material es introducido dentro de la ciudad para que surja lo impensable, lo imposible. Es un poner delante para expulsar. Edipo sufrió tal expulsión, pues su conducta era un peligro político. Su figura se hace arquetípica. Sófocles la lleva a la cumbre y luego deja que se desplome estrepitosamente. Edipo confía en la felicidad, como todo hombre, sin reparar que sólo es una morada frágil. Su inteligencia sagaz lo convierte en rey pues vence a la Esfinge, pero, quizá, no ve que "la creación y la vida misma sólo se definen por una especie de rigor, y por lo tanto de crueldad fundamental, que lleva a las cosas a su final ineluctable"'. Sófocles, despliega en el hombre Edipo este rigor. Al comienzo lo presenta como el sabio que con clarividencia conquista el poder de Tebas y, sin saber que es el asesino de su padre y esposo de su madre, cumple con aquel rigor ineluctable. La ambigüedad se traslada por la escena, porque es la propia ambigüedad de la naturaleza humana, que unas veces goza de una dicha indescriptible y otra de desventuras funestas. Dice Edipo delante del pueblo que fue a suplicarle que lo libere de la peste: "he venido en persona, yo, el llamado Edipo, famoso entre todos". ${ }^{8}$ En tanto, la ciudad lo considera "el primero de los hombres en los sucesos de la vida y en las intervenciones de los dioses". También, en la antistrofa 2 le anuncian: "Tú, que, tras disparar el arco con incomparable destreza, conseguiste una dicha por completo afortunada" ${ }^{10}$. Aquí tenemos el rostro triunfante del héroe. La ciudad lo glorifica y enaltece por su juicio recto. Edipo es discernimiento salvador.

Pero el arte teatral continúa, y sobre los elogios caerá lo implacable,

\footnotetext{
${ }^{7}$ Artaud, 1964: 105.

${ }^{8}$ Sófocles, 1977: 7.

${ }^{9}$ Sófocles, 1977: 32.

${ }^{10}$ Sófocles, 1977: 1197 (Antistrofa 2).
} 
confirmando que "toda ascensión es un desgarramiento"11. Esta es la crueldad a la que alude Artaud. Dice: "toda vida más fuerte se abre paso a través de las otras"12. En efecto, una nueva vida comienza a empujar a la anterior. A la vida en la cual era rey, esposo y sabio, empuja la nueva vida que le espera en la soledad. Es azote de sí mismo, no por una cuestión psicológica ni de maldad natural, sino porque, en palabras de Antonin Artaud: "El tema de Edipo rey es el incesto, y alienta en la obra la idea de que la naturaleza se burla de la moral; y de que en alguna parte andan fuerzas ocultas de las que debiéramos guardarnos, ya se llame destino o de cualquier otro modo". ${ }^{13}$ Estas fuerzas, lejanas al orden positivo y racional, sólo se padecen. Vernant lo dice así: "El parricidio, el incesto no corresponden ni al carácter de Edipo, su ethos, ni a una falta moral, adikía, que hubiera cometido" ${ }^{14}$. Esas aberraciones se deben a una fuerza que arrasa, o a la "crueldad en el sentido de apetito de vida, de rigor cósmico y de necesidad implacable". ${ }^{15}$ No obstante, para vivir sin terrores las sociedades "prefieren" inventar diques religiosos, científicos o jurídicos. La tragedia, en su trasfondo, retorna el carácter nada excepcional de estas transgresiones.

\section{El devorar como forma vital.}

Pensar las tragedias es aceptar una tensión insuperable, desechándose cualquier síntesis superadora. El corazón trágico golpea al ritmo de esta tensión inacabable. En efecto, las dos cegueras de Edipo no resuelven el incesto y tampoco la "trasgresión".

Ahora bien, uno de los posibles caminos en el que la obra Edipo Rey canaliza esta tensión es en el carácter simbólico que se halla en la Esfinge y en la peste. Es decir, quizá no sea sólo parte de la fortuna que Edipo al ingresar a Tebas tropiece con una devoradora como la Esfinge. Edipo abandona Corinto, temeroso por el vaticinio del oráculo. Al hacerlo empieza a ser devorado por el viaje. Los acontecimientos tebanos comienzan a deglutirlo. Llega a Tebas luego de matar a Layo, su padre. Esta ciudad "devora" al viajero que huyó de Corinto. El hombre común que es, luego de vencer a la Esfinge, desaparece tras la corona de rey y de esposo. Por último, todo este torbellino de sucesos, junto al cúmulo de dicha y felicidad que le otorgara el poder, comienza a apagarse mientras la imagen de rey es deglutida por la del errante ciego. Se convierte así en su propio devorador en el momento mismo que descubre verdaderamente quién es. Edipo a esta altura es representación del caos. Su ser

\footnotetext{
${ }^{11}$ Artaud, 1964: 105.

${ }^{12}$ Artaud, 1964: 105.

${ }^{13}$ Artaud, 1964: 120.

${ }^{14}$ Vernant, 2002: 113.

${ }_{15}$ Artaud, 1964: 105.
} 
padece el desorden de una ciudad contagiada por una epidemia. La analogía es viable siempre que aceptemos que una peste desata caos, exceso y confusión. Vayamos a ese panorama ampliado. Escribe Sófocles: "La ciudad, como tu mismo puedes ver, está ya demasiado agitada y no es capaz todavía de levantar la cabeza de las profundidades por la sangrienta sacudida. Se debilita en las plantas fructíferas de la tierra, en los rebaños de bueyes que pacen y en los partos infecundos de las mujeres ${ }^{16}$. La normalidad se ve interrumpida. En una epidemia gobiernan situaciones signadas por la agitación y la confusión. Edipo experimenta ambos signos por medio de los acontecimientos que lo dominan. Las certidumbres entran en una zona conflictiva. Si la peste se caracteriza por la hybris, desmesura, quién mejor que él la simboliza. Edipo, como la ciudad apestada, es arrastrado por un torbellino que desconoce. Otros vínculos entre Edipo y la peste son la destrucción y la muerte gratuita: Layo, los ciudadanos, Yocasta. Aquí es posible imaginar una triple alianza: Edipo, la peste y el teatro artaudeano. Escribe Artaud: "Hay en el teatro como en la peste, algo a la vez victorioso y vengativo" ${ }^{17}$. Más aún, la peste "toma imágenes dormidas, un desorden latente y los activa de pronto transformándolos en los gestos más extremos; y el teatro toma también gestos y los lleva a su paroxismo"18.

\section{Conclusión}

Intentamos, a partir de la tragedia Edipo Rey, resaltar la precariedad humana y cómo el mundo puede tornarse un lugar extraño, como el propio cuerpo cuando la enfermedad lo avasalla. Las tragedias se desarrollaron al "amparo" de esa precariedad. En sí mismo el teatro trágico tomó conciencia de ello, quizás esta sugerencia dentro de la tragedia en cuestión sea elocuente: "ningún mortal puede considerar a nadie feliz con la mira puesta en el último día, hasta que llegue al término de su vida sin haber sufrido nada doloroso" ${ }^{19}$.

Otra cuestión que quisiera destacar en este cierre es lo que atañe a la territorialidad de la escena. No al espacio geográfico sino al topos existencial. Dice Vernant: "El dominio propio de la tragedia se sitúa en esa zona fronteriza en la que los actos humanos vienen a articularse con las potencias divinas" ${ }^{20}$. La escena se enmarca en un espacio "entre". Es un espacio de desgarro y oscuridad. En él crecen los sueños prohibidos. Esos sueños en los cuales el alma, no repara, según Platón, "en violar con la imaginación a su madre, o en unirse a

\footnotetext{
${ }^{16}$ Sófocles, 1977: 23 ss.

${ }^{17}$ Artaud, 1964: 27.

${ }^{18}$ Artaud, 1964: 27.

${ }^{19}$ Sófocles, 1977: 1529.

${ }^{20}$ Vernant, 2002: 85.
} 
cualquiera, sea quien fuese, hombre, dios o animal" ${ }^{21}$. En este espacio teatral quedan fusionados los límites y la apertura en el que todo, absolutamente todo, puede suceder. Por eso Artaud insiste en decir que la representación teatral "nos restituye todos los conflictos que duermen en nosotros, con todos sus poderes y da a esos poderes nombres que saludamos como símbolos". ${ }^{22}$ Son esos símbolos escénicos los que hacen de este teatro, un lugar en el que el centro de lo que acontece esté en constante desplazamiento. El sitio está entre la humanidad y esos demonios dormidos que empujan a conductas infernales. El teatro es el arte que nos "alimenta" de esa angustiante encrucijada, dejándonos en ella. El personaje Edipo es encrucijada. Vive entre la dicha y el tormento, entre lo bello y lo espantoso: es padre y hermano, hijo y marido, es asesino de su propia sangre, es salvador y destructor de la misma ciudad. Por eso la tragedia, deja que el hombre se presente, como "una especie de monstruo incomprensible y desconcertante"23. Desconcierto fatal que le anuncia que en él merodea sin asentimiento la perdición.

\footnotetext{
${ }^{21}$ Platón, 1985: IX, 571c

22 Artaud, 1964: 27.

${ }^{23}$ Vernant, 2002: 84.
} 


\section{Bibliografía}

Artaud, Antonin (1964), El teatro y su doble, Argentina. Editorial Sudamericana. Bataille, G. (1972), La experiencia interior, Madrid, Taurus Ediciones.

Platón (1985), República, Buenos Aires, Editorial Universitaria de Buenos Aires.

Sófocles (1977), Edipo Rey, Barcelona, Editorial Planeta-De Agostini.

Vernant, Jean-Pierre - Vidal-Naquet, Pierre (2002), Mito y tragedia en la Grecia antigua, Vols. I y II, Barcelona, Ediciones Paidos Ibérica. 